\title{
Materiality and Genre in the Study of Discourse Communities
}

\author{
Amy J. Devitt, Anis Bawarshi, and Mary Jo Reiff
}

0 ver the past two decades the concept of discourse community has been one of the most hotly contested notions in the field, subject to the range of by now well-known critiques that claim it is too utopian, hegemonic, stable, and abstract. ${ }^{1}$ Abstracted from real social situations, discourse communities may appear stable to advocates and critics assuming an imaginary consensus and a shared purpose that do not reflect real experience within communities. The concept of discourse community as stable and utopian has been, to some, so seductive that it both conceals the language and the social practices that take place within it and distracts researchers from examining how its internal workings may be recognized and studied. As a result, the concept of discourse community remains of limited pedagogical value.

To make communities tangible and their discourse actions palpable to students, writing teachers have begun to use ethnographic research, which, while valuable in locating the study of discourse within the behaviors of real communities, can be difficult to implement in the classroom. According to Beverly Moss, "When ethnographers study a community as outsiders, they must spend a significant amount of

Amy J. Devitt is professor of English and Conger-Gabel Teaching Professor at the University of Kansas, where she teaches courses in writing and writing theory and English language studies. She is the author of Standardizing Written English: Diffusion in the Case of Scotland 1520-1659, articles on genre theory in College English and CCC, and two forthcoming books, a theoretical study of writing genres and a genrebased textbook for first-year writing courses (coauthored with Anis Bawarshi and Mary Jo Reiff). Anis Bawarshi is assistant professor of English at the University of Washington, where he teaches courses in rhetoric and composition. His book Genre and the Invention of the Writer (forthcoming) examines the relationship between genre and subject formation and what that relationship means for the study and teaching of writing. He has recently coedited, with Sidney I. Dobrin, A Closer Look: The Writer's Reader. Mary Jo Reiff is assistant professor of English and the director of the composition program at the University of Tennessee, where she teaches courses in rhetoric, writing, and technical communication. She has published articles in WAC Fournal, ZAC, Issues in Writing, and Writing on the Edge, and is currently completing a book on theories of audience.

College English, Volume 65, Number 5, May 2003

Copyright (C) 2003 by the National Council of Teachers of English. All rights reserved. 
time gaining access to the community and learning the rules of the community well enough to gather and eventually analyze the data" (161). The process of sifting through the massive quantities of information gathered and attempting to stake out some analytical claims can present a major hurdle, particularly for student ethnographers. How do ethnographers connect what community members know and do with what they say and how they say it - their language practices? Genre analysis has been responsive to such questions and links patterns of language use to patterns of social behavior, reflecting the composition researcher's "narrower concern with communicative behavior or the interactions of language and culture" (Moss 156). Genre study allows students and researchers to recognize how "lived textuality" plays a role in the lived experience of a group. Teaching students how to analyze genres can provide discipline and focus to the study of discourse communities.

During the last half-century, genre theory has been reconceived by literary and rhetorical theorists as, among other things, "sites of social and ideological action" (Schryer 208) —as parts of all social environments. Language genres in these contexts become less transparent and more constitutive, less the means of classifying texts and more the sites at which language's social character can be understood. In this sense language and its genres are as material as the people using them. As sites of social action, genres identify the linguistic ecology of discourse communities, making the notion of community more tangible for teachers and students.

In the three connected essays that follow, we use the idea of genre to study discourse communities. ${ }^{2}$ We examine several contexts of language exchange in which the use of genre theory may yield insight into teaching, research, and social interaction: legal practice, medical practice, and classrooms. Illustrating how genres can sometimes restrict access to communities, Amy Devitt examines jury instructions as a genre, considering how the genre affects the interactions of jurors in ways that inhibit the successful execution of their duties. Anis Bawarshi suggests how a specific textual genre, the patient medical-history form, works in and provides critical access into doctors' offices. Mary Jo Reiff discusses how the combination of ethnography and genre analysis can give teachers, researchers, and students clearer ways to understand their classrooms.

Together, the essays suggest how genre analysis contributes to the use of ethnomethodology as a research technique that focuses on language and society and that is especially eligible to contribute to the pedagogy of text-dependent subject matters. Whether we are studying academic, professional, or public communities, genres, considered as material entities, enable us to enrich the idea of a discourse community by giving discipline and focus to the study of the unities of language and society. 


\section{Where Communities Collide: Exploring a Legal Genre}

\section{Amy J. Devitit}

Contemporary genre analysis focuses on the actual uses of texts, in all their messiness and with all their potential consequences. Genre analysis also ties that use to actual language, to the smaller bits of language that alert analysts to underlying ideas, values, and beliefs. Such analysis often reveals the conflicts between communities that use a genre, conflicts often invisible to analysis that looks at discourse in terms of its communities alone. This essay analyzes some genres, particularly jury instructions, that are created within one professional community to be used by nonmembers of that community. While their purposes seem to be inclusive, to give nonmembers access to the community's knowledge, genre analysis strongly suggests that the specialist and nonspecialist users have different beliefs, interests, and purposes as well as levels of knowledge. The consequences for both the professional communities and the larger society are significant, potentially drawing the boundaries around professional communities even more tightly. In order to keep from substituting one abstracted concept for another, to keep from idealizing and homogenizing the realities of genres, students should also see the messiness and especially the exclusiveness of genres.

Because genres represent their communities, they effect and make consequential the communities' interests. But it is when genres encompass participants beyond a narrow community that the effects of those interests become most troublesome. Surprisingly, many genres are designed within one specialist community for functions to be filled by nonmembers of that community. Tax forms are designed by the IRS, but they are supposedly meant to be used by people who may know little of tax regulations. The fact that so many people hire specialists to complete their tax forms merely confirms the difficulty of the task of translating specialists' knowledge into laypersons' actions. An especially significant recent example is the ballot, both the propositions on it and the physical construction of it. Ballots are created by politicians but are completed by citizens. Ballots contain propositions that voters vote on, but the propositions are written by lawyers and knowledgeable proponents of an issue. To have our votes count, as we learned in the United States so vividly so recently, we must not only feel informed enough to be willing to walk into the voting booth (not always an easy task as the issues become ever more complicated and our politicians' explanations ever more simplified into sound bites); we must also be able to understand the ballot once we are in the booth. The genre of the ballot question makes it difficult to understand what is at issue. Typical ballot questions combine explanatory statements with legislative amendments, but the explanatory statements can rarely explain enough to enable the voter to understand the amend- 
ment. Even the physical layout of the ballot, we have learned, entails specialized but unstated knowledge, and good citizens must decipher where to punch, mark, and pull, and with what definiteness and strength. To mark a ballot seems a simple thing, but the community of election commissioners actually brings specialist knowledge to the interpretation of those ballots-knowledge not explained in the ballot genre. The specialists know what a chad is, for one thing, and understand what the machines will and will not count, how much must be punched for a vote to register. The specialists know that drawing a line through one candidate's name will render that ballot invalid, while the good citizen might know only that drawing such a line is a known way to register displeasure. Even without getting into the language of provisions, often unintelligible to even the most educated voters, the ballot as a genre includes complications and presumptions that serve the interests of the specialist creators but not of the nonspecialist users.

In fact, much of our civic lives involves genres that come out of a community of specialists, whether lawyers, legislators, or government employees. Doing our civic duty depends as much on our ability to understand and use genres accurately as it does on our willingness to be good citizens. Yet the difficulty remains of community-embedded genres producing action by nonmembers of that community. Although the borders of communities are more permeable and fluid than the community metaphor suggests, clashes of knowledge and perspective still result when specialists and nonspecialists meet, clashes that have consequences in terms of how participants interact, perform their actions, and produce certain effects in the world.

The inclusion of nonspecialists is vital to the U.S. judicial system, with the usually final decisions made not by all-knowing judges but by everyday citizens. Instructions to juries are designed to explain enough of the law so that a jury of peers can render an appropriate verdict. But jury instructions are written by lawyers, with their details hammered out by lawyers and the judge arguing privately, away from the ears of the jurors who must use them. By the time the judge gives a jury instructions, those instructions contain presumptions, implications, specifications known well by the law community but unknown to the unsuspecting jury members. The genre thus has a significance for the legal community that it does not have for the jurors. As a result, juries do not and cannot interpret the genre the way its creators intended, as lawyers would, and cannot render verdicts that follow those instructions fully and accurately, thus resulting in significant consequences, particularly for defendants.

One recent example turned on a single word (see Mathis). Michael Sharp was convicted of child endangerment in 1999 after he held on to his three-week-old daughter while police were trying to arrest him on an outstanding warrant. His girlfriend and a police officer testified that he seemed to be holding the baby carefully. Before long, Sharp handed the child to officers. At his trial, the judge in the 
case instructed the jury to find Sharp guilty if they found he had put the girl in a situation where her "body or health might be injured or endangered." The jury rendered a verdict of guilty. The problem, according to Sharp's lawyer and an appeals court, is that the word "might" has a different meaning in law than in common usage. The word has a different weight to each party; it is material in different ways. Courts define "might" as saying an action was probable, not merely possible. Since the jury instructions did not explain the court's meaning of "might," the appeals court overturned the verdict and ordered a new trial. As the appeals court judge wrote in his decision, "There is a very real possibility, especially under the facts of this case, that the jury would have returned a different verdict had the term 'might' been properly defined" (qtd. in Mathis). With the community of lawyers defining "might" differently than do nonmembers, can instructions to a jury ever specify the law sufficiently to let the jury do its job according to that law? The genre of jury instructions has a perhaps insurmountable task in needing to tell citizens unaware of legal technicalities how to follow the relevant law in making their decision, a task of making community members out of nonmembers, of getting nonmembers to enact and reproduce the agendas of a specialist community.

This difficulty is especially troubling in the particular jury instructions I have examined in detail, the instructions to a jury in the sentencing phase of a capital case-instructions to a jury deciding whether to sentence a defendant to death. Originally called in to examine potential bias in the pattern of instructions (a set of approved jury instructions that judges commonly use), I eventually worked to rewrite those instructions in order to make them clearer to an ordinary jury. What I discovered is that no matter how much I elaborated, no matter how many assumptions I made explicit, I could not capture in those instructions all the information that the lawyers considered relevant to the jury's task. Clarifying for the jury's purposes clashed with adhering to legal purposes. What seemed a reasonably straightforward genre when I began proved to be a genre mired in its specialized community's expectations and potentially misleading to its nonspecialized users. What was material to me and to juries was not material to lawyers and judges, and vice versa.

Part of the difficulty when specialized communities write to nonspecialist users lies in technical language, a difficulty commonly recognized and often addressed through defining key terms, but most of the difficulty comes from differences of interest and value that definitions cannot control. In capital cases, two key terms are "aggravating" and "mitigating," for juries must weigh aggravating and mitigating circumstances. These terms are so central to the law as well as to the task at hand that no definition or rewording could capture the full technical meaning of these terms to the courts. In addition, each potential juror may have a private sense of the value of these terms. But even greater difficulties arise from the use of common terms to serve specialist interests. The list of aggravating circumstances from the 
Pattern Instructions for the state of Kansas (a set of instructions modeled on existing instructions from other states) itemizes eight possible aggravating circumstances. Some of those circumstances appear to be matters of fact, though surely still contestable: that the defendant authorized someone else to commit the crime, that the defendant was imprisoned for a felony at the time, or that the defendant committed the crime for money, to avoid arrest, or to silence a witness. Other possible aggravating circumstances, though, require jurors to assess not only whether facts were proven but also the degree of seriousness of the crime: that the defendant previously "inflicted great bodily harm, disfigurement, dismemberment, or death on another," that the defendant knowingly "created a great risk of death to more than one person," or that the defendant "committed the crime in an especially heinous, atrocious or cruel manner." "The term "heinous,"” the instructions continue, "means extremely wicked or shockingly evil; 'atrocious' means outrageously wicked and vile; and 'cruel' means pitiless or designed to inflict a high degree of pain, utter indifference to, or enjoyment of the sufferings of others." The list of aggravating circumstances is full of gradable words with no standard of comparison: "great" bodily harm and risk of death, "serious" mental anguish or physical abuse. Mitigating circumstances similarly depend on judgments of "significant" histories, "extreme" disturbances or distress, "relatively minor" participation, or "substantial" domination and impairment. When I asked about providing some standard or clarifying what is legally defensible, I was told that there is no legally tested standard and so none could be provided.

In fact, the greatness or seriousness of the crime is precisely what the jury is being asked to evaluate. Yet nowhere do the instructions say that. Rather, the jury instructions follow the legal community's need for events to be based in fact rather than value, so circumstances are treated as either existing or not existing. That perspective appears explicitly in the next instruction about burden of proof: the State must prove "that there are one or more aggravating circumstances and that they are not outweighed by any mitigating circumstances." In fact, however, to decide whether an aggravating circumstance exists requires deciding whether the action was great, serious, or, in perhaps the most notorious language, "heinous." For a jury to decide that a crime was "especially heinous" and thus that an aggravating circumstance exists, the jury is told to define "heinous" as "extremely wicked or shockingly evil." Here in the courtroom, in the setting of this specialized community based in logic and reasoning, a jury of peers is told to "determine" and "consider" "evidence" that will allow them to decide "beyond a reasonable doubt" that a crime was "extremely wicked or shockingly evil." The clash of specialized standards with common values produces a very confused genre, not to mention jury. The material language of the genre produces material consequences, for the defendant as well as for the jury's actions and the legal community's use of those actions. 
One final example from these jury instructions reveals the subtle form this clash between members and nonmembers of specialist communities can take and how it materializes in actual practices, languages exchanges, and relations. In the instruction just examined, the jury is to decide that "there are one or more aggravating circumstances and that they are not outweighed by any mitigating circumstances." The jury is not told how to weigh these circumstances but rather how not to weigh them:

In making the determination whether aggravating circumstances exist that are not outweighed by any mitigating circumstances, you should keep in mind that your decision should not be determined by the number of aggravating or mitigating circumstances that are shown to exist. (Pattern 56.00-F)

The negatives in these several instructions and the ones that follow compound, to a point that I believe most jurors would have difficulty interpreting: their decision rests on doubting (but not by counting) that some circumstances are not outweighed by others so that the defendant will not be sentenced to death. When I tried to rewrite these instructions to clarify and simplify them, though, I found that those negatives contained vital specialist presumptions. At one point, I suggested the wording, "In determining whether mitigating circumstances outweigh aggravating circumstances, you should not decide by counting the number of mitigating or aggravating circumstances that you believe exist." That revision failed to capture several legal details. Of course, it is not a matter of the jurors believing circumstances exist; they have to be shown to exist, though elsewhere jurors can be persuaded that they exist. (Note again the insistence on circumstances simply existing or not, without acknowledging that the jury must evaluate the severity of the act.) Most seriously of all, the lawyers told me, I had changed the burden of proof. The prosecutors must show that aggravating circumstances exist, first of all, and second that they are not outweighed by mitigating circumstances. The defense does not have to prove that mitigating circumstances outweigh aggravating circumstances. To serve their own purposes, jurors might well begin deliberations by weighing mitigating against aggravating (being careful now not to count), without realizing that they were shifting the burden of proof. Because the materiality of any language depends on how different communities are invested in it, language is considered to be transparent both by jurors and by judges and lawyers. Written by lawyers, the language of jury instructions assumes that the jurors will, like the lawyers, know what is important and know what to do, that the genre will enable nonmembers to behave as members would.

No amount of explication, definition, or simplification can capture the specialized legal knowledge required for a just and fair decision, as defined by the court system. The legal community—and our society—needs these distinctions, estab- 
lished by law and precedent, to be maintained. The genre of jury instructions is meant to guide jurors in following that law. Yet the complexity of the law, the technical nature of its precedents, and, in short, the embeddedness of the genre in its community make it impossible for nonspecialists to understand fully as a specialist would, no matter how well-written, detailed, or rhetorically sophisticated the jury instructions.

Leading to the linguistic and technical complexity of jury instructions is the rhetorical complexity of the situation. Lawyers and judges are in the position of maintaining the law while needing to achieve their goals through the actions of others, the relatively ignorant jurors. Jurors are in the position of deciding another human being's fate based on society's values, while being told to disregard their instincts unless they conform to the law, a law they do not fully understand. The genre of jury instructions attempts to enact those behaviors, but, like all genres, its effects depend on the actions of politically and morally interested people. Jurors must somehow address or respond to the jury instructions, giving those instructions material consequence, but jurors can respond by acting against those instructions. This reality is revealed most explicitly in the concept of jury nullification, in which individual jurors vote not according to the evidence and the law but according to their beliefs about the rightness of the law, the oppression of the defendant's group, or other beliefs and values not represented in the jury instructions or the facts of the case. Even without such explicit political motivation or deliberateness, jurors often decide in ways that may or may not match even the jurors' understanding of the instructions they received. The most immediately significant genre in a capital case is the verdict, a genre with real consequences. Jury instructions try to influence that verdict, but their effectiveness depends not just on the legal community's ability to convey important specialist information but also on the jury's ability and willingness to conform to their expected role. Jury instructions also try to influence future legal actions, whether appeals of this particular case or future similar cases. The material effects of the genre for the legal community cannot be captured in the jury's actions or the verdict alone. Although designed to transcend the narrow interests of the legal community, jury instructions also return to that community, becoming another potential precedent and more specialist knowledge.

Tax forms, ballot questions, jury instructions—all genres designed precisely to bring specialist and nonspecialist communities together-all function in complex linguistic, informational, and rhetorical situations. All genres exist through and depend on human action, so these community-spanning genres, too, depend on the cooperation of participants from multiple communities, on people accepting the roles the genres assign to them and on being able to carry out the tasks expected of them. Since people in fact often have conflicting interests and motivations, the effects of such genres may be unpredictable. Lawyers and judges, for example, surely 
want a fair and just verdict, but their community's values also emphasize winning, not being overturned on appeal, and building reputations as well as bank accounts. The general populace from which jurors come also wants a fair and just verdict, but that desire interacts with popular notions of fairness and rightness and with individual moral differences, ideas about social injustices, and experiences with the legal system, as well as with concerns for a speedy return to jurors' regular lives and paychecks.

The communal agendas of those who create genres may conflict with the interests of those who use them-users who would ideally reproduce the ideologies and agendas of the legal community, but who do not. To say that the genre of jury instructions-and other similar genres-simply cross community borders is to simplify the complex interaction of individuals and groups, motives and agendas, and to ignore the conflicting consequences of one genre serving different groups. To understand more fully these genres is to understand more fully how the generic materialities are their uses-in-contexts, with serious effects on people's lives.

\section{Using Genre to Access Community: The Personal Medical History Genre as "Form of Life"}

\section{Anis Bawarshi}

As Bruce Herzberg describes it, the concept of discourse community is based on the assumption that "language use in a group is a form of social behavior, that discourse is a means of maintaining and extending the group's knowledge and of initiating new members into the group, and that discourse is epistemic or constitutive of the group's knowledge" (qtd. in Swales 21). Hence the idea of discourse community is built on the premise that what we know and do is connected to the language we use. Such an understanding acknowledges the materiality of language, but does not necessarily give us access and insight into the complex motives, relations, commitments, and consequences that accompany the use of language to get things done in specific situations, as Devitt's examination of jury instructions describes.

Analyzing genres within their lived contexts reveals to students, teachers, and researchers the material strength of those communities and their power over members and nonmembers alike. Whether examining legal, medical, or pedagogical genres, genre study gives us specific access to the sites of language use that make up communities, in all their complexity. When we use genre analysis as ethnomethodological technique, we not only gain access into communities, but also begin to recognize how "lived textualities" interact with and transform "lived experiences." Such recognition becomes especially significant when we are teaching students how to use language to participate more knowledgeably and critically in various sites of 
language use. Using the genre of the Patient Medical History Form as an example, I demonstrate how genre analysis gives access to the workings of discourse communities in a way that renders the idea of a discourse community a more tangible, helpful concept for teachers, students, and researchers.

Attention to the Patient Medical History Form (PMHF), a commonly used medical genre, suggests how focusing on a specific textual genre helps us to identify a discourse community by relating it to a specific site of interpersonal activity that most of us have experienced. The PMHF is a good way to understand something about how doctors function and how they treat us as patients. At the same time, it also serves to show that the community is not just a backdrop to language behavior, but a growing, moving environment that includes texts and speech as its constituents, just as people are its members. We compose our discourse communities as we write and speak within them. And genre is a key part of this process.

The idea of genre, despite the work of scholars in literary and rhetorical studies over the last few decades, is still more often than not understood as a transparent lens or conduit for classifying texts. The word genre, borrowed from French, means "sort" or "kind," and to study sorts or kinds of things is not thought to be as substantial as to study the things themselves. Genres appear to be transparent when they are understood as ways of classifying texts. But recent scholarship in genre theory has tried to dispel this view by stipulating genres to be language forms that have identifiable and changing roles in interpersonal relations and in larger collective contexts. One of the roots of the word genre is the Latin cognate gener, meaning to generate. This etymology suggests that genres sort and generate. Genres organize and generate the exchanges of language that characterize what we are referring to in this essay as discourse communities.

Carolyn R. Miller has defined genres as typified rhetorical ways of acting in recurring situations (159). Following Miller, Charles Bazerman defines genres as social actions. He writes:

Genres are not just forms. Genres are forms of life, ways of being. They are frames for social action $[, \ldots$. . locations within which meaning is constructed. Genres shape the thoughts we form and the communications by which we interact. Genres are the familiar places we go to create intelligible communicative action with each other and the guideposts we use to explore the unfamiliar. (19)

To claim that genres are environments within which familiar social actions are rhetorically enacted is to understand them as language practices. David Russell calls them "operationalized social action[s]" (512) within which communicants come to know specific situations as they enact them in language practices. The extent to which genres organize and generate discourse communities appears vividly in the example of the physician's office. A physician's office might be considered a local discourse community and part of a wider one insofar as its members share language 
practices and have comparable purposes. These purposes are enacted in social relations that are partly marked by the PMHF, a genre that within the medical profession is one of its Wittgensteinian "forms of life." As patients we recognize this form on our first visit to a physician as one that solicits information regarding our physical data (sex, age, height, weight, and so on) as well as medical history, including prior and recurring physical conditions, past treatments, and a description of current physical symptoms. Included in the genre is also a request for insurance carrier information and then a consent-to-treat statement and a legal release statement, which patients must sign. The form is at once a patient record, a legal document, and an element in a bureaucracy, helping the doctor treat the patient and presumably protecting the doctor from potential lawsuits.

But these are not the genre's only functions. The PMHF also helps organize and generate the social and rhetorical environments within which patients and doctors speak to one another. For example, the fact that the genre is mainly concerned with a patient's physical symptoms suggests that one can isolate physical symptoms and treat them with little to no reference to the patient's state of mind and the effect that state of mind might have on these symptoms. This genre assumes that body and mind are separate and also helps to perpetuate this belief. In so doing, the PMHF reflects Western notions of medicine, notions that are rhetorically naturalized and reproduced by the genre and that are in turn embodied in the way the doctor recognizes, interacts with, and treats the patient as a synecdoche of his or her physical symptoms. For example, it is not uncommon for doctors and nurses to say "I treated a knee injury today" or "The ear infection is in room 3" when referring to patients. The PMHF is at work on the individual, urging the conversion of a person into a patient (an embodied self) prior to his or her meeting with the doctor at the same time as it is at work on the doctor, preparing him or her to meet the individual as an embodied "patient." In this way, the genre is a site for the exchange of language within which participants influence one another and identify their discourse communities. The mental state of patients may not be considered material to the injury or illness; conversely, the form tends to discourage patients' reporting of mental or emotional circumstances of injury and illness, with the result that they may be incompletely or inaccurately treated.

The PMHF is one of several related genres that constitute a community one could call "the physician's office." Each of these genres-which could include greetings, oral symptom descriptions, prescriptions, referrals, physical gestures, and explanatory metaphors-is a form of life that is part of other social practices (relations between doctors and patients, nurses and doctors, doctors and other doctors, doctors and pharmacists, and so on), all of which add up to what Amy Devitt has called "genre sets." As such a set, the physician's office is a multigenre community constituted by several interconnected genres, some of which may represent conditions of 
social conflict. Members of this community "play" various language games: they have multiple ways of identifying themselves and relating to others within the community. In this way genres help counter the idealized view of discourse communities as discursive utopias constituted by homogeneity and consensus. As Bazerman notes, "[G]enres, as perceived and used by individuals, become part of their regularized social relations, communicative landscape, and cognitive organization" (22). These social relations, communicative landscapes, and cognitive organizations, however, are always shifting, always multiple, as they are enacted by individuals within different genres. We can think of genres as the operational sites of discourse communities.

Teachers, students, and researchers gain ethnomethodological access to discourse communities through genre analysis, which enables them to observe how and why individuals use language in specific settings to make specific practices possible. Recognizing the presence of genres helps us to recognize the palpability and complexity of our discourse communities, to reduce their abstract, symbolic status, thereby making discourse communities more visible and accessible to ethnographic inquiry.

The following example, from the research of Anthony Paré, suggests the materialization of genre and its value for ethnographic inquiry. Paré records a portion of a conversation between a social work student, Michael, and his supervisor. The supervisor is responding to Michael's draft of an assessment report, a typical social work genre:

That's right. So you wrote here, "I contacted." You want to see it's coming from the worker, not you as Michael, but you as the worker. So when I'm sometimes in Intake and [working] as the screener, I write in my Intake Notes "the screener inquired about." ... So it becomes less personal. You begin to put yourself in the role of the worker, not "I, Michael." [I]t's a headset; it's a beginning. And even in your evaluations ... the same thing: as opposed to "I," it's "worker," and when we do a CTMSP for placement for long-term care, "the worker." So it positions us, I think. It's not me, it's my role; and I'm in the role of professional doing this job. (67)

In this example, we notice the extent to which the genre becomes the site for the exchange of language and social interaction. The student, Michael, is learning to "play a language game," the genre of the "assessment report." This exchange between social work student and supervisor takes place within the genre, a genre that constitutes the social roles and material relations of social workers-roles as impersonal observers and "professionals"-thus constituting, in part, the community of social work.

It is in the sum of exchanges such as this one, exchanges constituted by the various and sometimes conflicting genres used in different settings, that individuals compose in and compose discourse communities. 
Accessing Communities through the Genre of Ethnography: Exploring a Pedagogical Genre

Mary Jo REIFF

In "The Life of Genre, the Life in the Classroom," Charles Bazerman describes genres as the "road maps" that student writers consult as they navigate "the symbolic landscape" (19). As typical responses to repeated social situations, genres are rhetorical maps that chart familiar or frequently traveled communicative paths and provide guideposts as writers adapt to unfamiliar academic terrain and study parts of society beyond the classroom. Thus understood, genre analysis is well suited for use in ethnographic approaches to writing pedagogy. Exploring the implications of genre for rhetorical instruction, Carolyn R. Miller observes, "For the student, genres serve as keys to understanding how to participate in the actions of a community" (165). Since genres embed and enact a group's purposes, values, and assumptions, they can illuminate a community's discursive behaviors; however, the question of how students gain entrance to and participate in this discursive landscape remains a source of debate.

Taking up the issue of genre analysis in writing instruction, Aviva Freedman poses the following question: "Can the complex web of social, cultural and rhetorical features to which genres respond be explicated at all, or in such a way that can be useful to learners?" (225). Freedman objects to studying genres outside the contexts in which they are found, abstracting them from living situations. Her concern is shared by David Bleich, who argues that genres-like all language use-are not eligible for study once they are considered to be independent of their contexts of use: "[T] he process of study lies always within the language-using society. There is no sense in which the language one tries to understand can be thought of as located outside the living situation in which the thinker (who is all the while using the language) is working" (122). Studying genres within the actual contexts of their usewithin real human groups-requires "insider" research (Freedman 234), a type of research that can be carried out through the use of ethnography. With its emphasis on participant/observation and on hands-on attention to communities, ethnography enables students to examine communicative actions within living situations and to see first-hand how communities use genres to carry out social actions and agendas.

To understand genres as situated actions, Miller has advocated an ethnomethodological approach, one that "seeks to explicate the knowledge that practice creates" (155) - knowledge rooted in the materiality of circumstances and conditions of actual use of genres. Similarly, Bazerman has argued that "[b]y forging closer links with the related [enterprise] of [...] ethnomethodology, genre analysis can play" a 
major role in investigating communication within social organizations (23). I consider how ethnomethodology as an academic research method and ethnography as a genre of writing that is particularly useful in writing pedagogy can provide more authentic language tasks in classrooms and can give students better access to contexts of language use beyond the classroom.

Certainly ethnography has become an increasing presence in composition as a research method and a pedagogy. However, Wendy Bishop and others distinguish between the general research method of ethnography and the more focused ethnographic writing research, which usually explores particular sites of literacy or particular literacy practices. Clarifying this distinction, Beverly Moss notes, "While ethnography in general is concerned with describing and analyzing a culture, ethnography in composition studies is [. . . concerned more narrowly with communicative behavior or the interrelationship of language and culture" (156). Ethnography in composition, particularly as a pedagogical approach, is concerned with the general as well as the particular: with the lived experience or behavior of a culture (as in anthropology or sociology) and with the way in which this behavior manifests itself rhetorically.

If ethnographies are understood as studies of communities and their social actions and genres taken to be rhetorical manifestations or maps of a community's actions, then genre analysis is an especially helpful path in ethnographic methodology. In order to investigate a community's social motives and actions, student ethnographers can examine the uses of language associated with these actions (the group's spoken and written genres) by gathering samples of the genre and analyzing what the rhetorical patterns reveal about the community—its purposes, its participants, and its values, beliefs, and ideologies. Ethnography is both a genre (a research narrative) and a mode of genre analysis—a research methodology used to grasp cultural beliefs and behaviors, often through the examination of genres, which are "frames for social action" (Bazerman 19). In "Observing Genres in Action: Towards a Research Methodology," Anthony Paré and Graham Smart propose how ethnographic inquiry and genre analysis work together. Understanding genre as "a rhetorical strategy enacted within a community," they say that "a full appreciation of the part that [social] roles play in the production and use of generic texts can only be gained by observing an organization's drama of interaction, the interpersonal dynamics that surround and support certain texts" (149). Ethnographic observation of a community that foregrounds genre analysis allows researchers to explore more fully the complexity of the group's social roles and actions, actions that constitute the community's repeated rhetorical strategies, or genres.

While students don't have extended periods to carry out ethnographic studies, they can carry out what Bishop has labeled "mini-ethnographies," smaller-scale studies 
that explore particular literacy events or local phenomena in a community. Marilyn Chapman, in an essay on the role of genre in writing instruction, lists three main teaching interests with regard to genre: "learning genres, or widening students' genre repertoires; learning about genres, or fostering awareness [. . . and learning through genres, or using genres as tools for thinking and learning in particular situations" (473). Using ethnography in the classroom would address these goals and would have students learn one research genre (ethnography), while they simultaneously use ethnographic techniques to learn about and through other genres. As a result, incorporating ethnography into the classroom ensures that all three of the above interrelated goals are met, giving students access to the material practices of both the classroom community and communities beyond the classroom.

With regard to the first goal, when students are assigned ethnographies, they learn a new genre to add to their repertoire, a research genre that carries with it particular purposes, participants, and agendas. According to Moss, the main purpose of this genre is "to gain a comprehensive view of the social interactions, behaviors, and beliefs of a community or a social group" (155). This purpose casts student researchers, as users of the genre, into dual roles as both participants in the community and observers of the community's interactions. Moss compares the ethnographer to a photographer who both "takes pictures of the community" and is "in the picture at the same time" (154). The process of inquiry and firsthand participantobservation entailed by this genre requires that students engage in several rhetorical strategies: critical and reflective thinking (when deciding upon what actions and artifacts to capture through pictures); what Clifford Geertz called "thick description" (when developing the pictures so that the details are vibrant and the images come to life); an awareness of the multiple audiences who will view the pictures; and, as someone who is also "in the picture," development of an ethos as an expert or producer of knowledge. These rhetorical strategies related to purpose, audience, and persona give rise to a number of rhetorical features and conventions. In order to address an audience and create a credible ethos, writers might include a description of the data-collection methods, an explanation of the data, and a discussion of their implications. To create a representation of lived experience, students might incorporate details, dialogue, and direct quotations from community participants. Students learn a new genre as they employ patternings of language and rhetorical strategies to create an empirically grounded representation of social realities.

The second goal, learning about genres and fostering genre awareness, is also accomplished through the use of ethnography. Since the main goal of an ethnographer, according to Moss, is to gain "increased insight into the ways in which language communities work" (170), it follows that the oral and written genres of groups will play a central role in the investigation of the social context of language use. 
Geertz defines ethnographies as "interpretations of interpretations" (9), meaning that students must study the genres that community members use to interpret their contexts in order to fully understand and themselves interpret the community.

For example, Susan, a pre-law student in my advanced composition class, carried out a mini-ethnography on the law community. In order to find out how novice members of the community become socialized to the values, beliefs, and knowledge of the community, Susan considered genres such as opinions, wills, deeds, and contracts; she focused her study on the genre of case briefs. She collected samples of constitutional law briefs, which, she recognized, "illustrated the legal community's shared value of commitment to tradition, as well as the need for a standard and convenient form of communicating important and complex legal concepts." While Susan also conducted interviews and observed lawyers in a small local firm, the genre analysis was the focus of her study, which helped to teach others about the habits and traditions of the law community. She learned about the generic features of case briefs, such as the technical terminology, rigid format, and formal style, and she became more aware of how these formal practices reflected and reinscribed the goals of the community. Recognizing that all the briefs follow the same format of presenting sections labeled "case information," "facts of the case," "procedural history," "issue," "holding," and "court reasoning," she surmised that "[e]ven the rigid structure of the format can help with our analysis by suggesting the community's emphasis on logic and order, which are two esteemed values of the profession." For students like Susan, using genre as a site for ethnographic inquiry cultivates a consciousness of the rhetorical strategies that characterize the daily work of a specific kind of professional community. By learning a community's language through its genres, students then have a more realistic sense of what it is to be a member of the community.

The third genre-related teaching interest is learning through genres, using genres to think about and understand particular situations. Ethnography gives students experience with genre analysis and with how research processes change received genres of reporting knowledge. As ethnographers seek to describe a community, they use various genres for research. Before beginning the study, students may write letters to seek permission to observe groups, or they might write proposals for their research or research plans and agendas. During the research, they use several genres such as field notes, journals or activity logs, project chronologies or summaries, progress reports, interview transcripts, even maps. When the research is completed, they may try to write in other genres that the situation warrants, like thank-you notes, self-assessments, peer assessments, or abstracts. Class time might be spent discussing the genre of the interview or the different purposes of descriptive versus analytic field notes. These genres are resources for supporting or extending thinking. Students learn a research genre that depends on genre analy- 
sis; they also learn to use, adapt, and possibly change a variety of genres during the different processes of inquiry.

When students carry out ethnographies, they become researchers who are also active social figures participating in and observing how people integrate their language genres with their wider collective purposes. Shifting the usual teacher/student relationship, students assume the role of investigators who are learning to speak from their own authority as researchers. As a result, classrooms become, in part, research sites at which all members are investigating, teaching, and learning. The research genre of ethnography creates a culture of inquiry, with language and genre the foci that lead to combined knowledge of rhetoric, collective values, and the broader purposes of different communities.

Students in these classrooms also help to create their own community while observing "meaningful discourse in authentic contexts," thus accomplishing what Freedman defines as the necessary criteria for learning genres: "exposure to written discourse" combined with "immersion in the relevant contexts" (247). Student ethnographers are able to study the uses of language and genre within real contexts, situations in which "speakers are alive, functioning, changing and interacting" (Bleich 120). Because ethnography is both a research genre (which functions for academic communities) and an approach to genre analysis (which explores communicative actions in groups outside the classroom), ethnographic work in class enables students to compose communities while composing in communities.

\section{Notes}

1. See, for example, John Trimbur's call for a rhetoric of dissensus-a view of community based in "collective explanations of how people differ, where their differences come from, and whether they can live and work together with these differences" (610). See also Bizzell, Harris, Kent, and Leverenz.

2. We thank the many participants in a lively exchange at the 2001 Conference on College Composition and Communication, whose comments on our initial presentation have helped us clarify and elaborate our arguments.

\section{WORKS Cited}

Bazerman, Charles. "The Life of Genre, the Life in the Classroom." Genre and Writing: Issues, Arguments, Alternatives. Ed. Wendy Bishop and Hans Ostrom. Portsmouth, NH: Boynton, 1997. 1926.

Bishop, Wendy. Ethnographic Writing Research: Writing It Down, Writing It Up, and Reading It. Portsmouth, NH: Boynton, 1999.

Bizzell, Patricia. Academic Discourse and Critical Consciousness. Pittsburgh: U of Pittsburgh P, 1992.

Bleich, David. "The Materiality of Language and the Pedagogy of Exchange." Pedagogy 1 (2001): 11741.

Chapman, Marilyn L. "Situated, Social, Active: Rewriting Genre in the Elementary Classroom." Written Communication (1999): 469-90. 
Devitt, Amy J. "Intertextuality in Tax Accounting: Generic, Referential, and Functional." Textual Dynamics of the Professions: Historical and Contemporary Studies of Writing in Professional Communities. Ed. Charles Bazerman and James Paradis. Madison: U of Wisconsin P, 1991. 335-57.

Freedman, Aviva. "Show and Tell? The Role of Explicit Teaching in the Learning of New Genres." Research in the Teaching of English 27 (1993): 222-51.

Geertz, Clifford. The Interpretation of Cultures. New York: Basic, 1973.

Harris, Joseph. A Teaching Subject: Composition since 1966. Englewood Cliffs, NJ: Prentice, 1997.

Kent, Thomas. "On the Very Idea of a Discourse Community." CCC 42 (1991): 425-45.

Leverenz, Carrie Shively. "Peer Response in the Multicultural Composition Classroom: Dissensus-A Dream (Deferred)." 7AC 14 (1994): 167-86.

Mathis, Joel. "Appeal Brings Defining Moment." Lawrence fournal-World 4 Nov. 2000: B1.

Miller, Carolyn R. "Genre as Social Action.” Quarterly fournal of Speech 70 (1984): 151-67. Rpt. in Genre and the New Rhetoric. Ed. Aviva Freedman and Peter Medway. London: Taylor, 1994. 23-42.

Moss, Beverly. "Ethnography and Composition: Studying Language at Home." Methods and Methodologies in Composition Research. Ed. Gesa Kirsch and Patricia Sullivan. Carbondale: Southern Illinois UP, 1992. 153-71.

Paré, Anthony. "Genre and Identity: Individuals, Institutions, Ideology." The Rhetoric and Ideology of Genre: Strategies for Stability and Change. Ed. Richard M. Coe, Lorelei Lingard, and Tatiana Teslenko. Cresskill, NJ: Hampton, 2002. 57-71.

Paré, Anthony, and Graham Smart. "Observing Genres in Action: Towards a Research Methodology." Genre and the New Rhetoric. Ed. Aviva Freedman and Peter Medway. Bristol: Taylor, 1994. 146-54.

Pattern Instructions for Kansas—Criminal 3d. Sect. 56.00-B-H. 2000.

Russell, David R. "Rethinking Genre in School and Society: An Activity Theory Analysis. Written Communication 14 (1997): 504-54.

Schryer, Catherine. "Records as Genre.” Written Communication 10 (1993): 200-34.

Swales, John. Genre Analysis: English in Academic and Research Settings. Cambridge: Cambridge UP, 1990.

Trimbur, John. "Consensus and Difference in Collaborative Learning." College English 51 (1989): 60216. 